\title{
ALINHAMENTO POSTURAL DA COLUNA NO PLANO SAGITAL DE CRIANÇAS EUTRÓFICAS E ACIMA DO PESO EM FASE PRÉ-ESCOLAR E ESCOLAR: ESTUDO LONGITUDINAL
}

\author{
POSTURAL ALIGNMENT OF THE SPINE IN SAGITTAL PLANE OF EUTROPHIC AND \\ OVERWEIGHT CHILDREN IN THE PRESCHOOL AND SCHOOL PHASE: \\ LONGITUDINAL STUDY
}

\author{
Mariana Zingari Camargo \\ Dirce Shizuko Fujisawa \\ Orientador \\ Programa de Pós-Graduação em Ciências da Reabilitação \\ Universidade Estadual de Londrina \\ Universidade Norte do Paraná
}

Introdução: A identificação precoce das alterações posturais e de fatores agravantes se faz necessária para que a criança mantenha o alinhamento adequado. Objetivos: Descrever e caracterizar o alinhamento postural da coluna vertebral, em plano sagital, de crianças da fase pré-escolar à escolar. Dois estudos foram desenvolvidos: (1) caracterizar a postura da cabeça, cervical e ombros; (2) avaliar o alinhamento da coluna torácica e lombar e oscilação de tronco, no plano sagital, de crianças eutróficas e acima do peso corporal. Métodos: Em ambos os estudos, a amostra foi de 99 crianças, as avaliações realizadas em dois momentos, fase pré-escolar (5 e 6 anos) e escolar (de 8 a 11 anos). As avaliações foram por meio de análise antropométrica e fotogrametria computadorizada. As variáveis angulares e lineares avaliadas por meio da fotogrametria foram: ângulo sagital da cabeça, ângulo cervical, ângulo dos ombros, distância da cabeça, ângulo oscilação de tronco, ângulo torácico e ângulo lombar. Resultados: No primeiro estudo, diferenças foram encontradas entre as fases pré-escolar e escolar, mas apenas as variáveis ângulo do ombro $(A O)$ e distância da cabeça (DC) foram significantes (AO $=32,79[30,49-35,09]$ e $35,84[33,53-38,15] p$ $=0,026$, respectivamente; $\mathrm{DC}=8,40[8,07-8,73]$ e $11,23[10,94-11,52] p<0,001$, respectivamente).
A correlação positiva foi obtida entre a distância da cabeça e massa corporal $(r h o=0,597, p<0,001)$. No segundo estudo, foram identificadas diferenças entre os grupos eutrófico e acima do peso, na fase escolar, para as variáveis ângulo torácico-AT(206,07 $\pm 7,31$ e $211,63 \pm 5,68 ; p<0,001)$ e ângulo lombar-AL $(104,32 \pm 7,93$ e $97,13 \pm 9,32$; $p<0,001)$. Observouse que os valores obtidos de AT e AL dos escolares sofreram influência na postura dos pré-escolares. Conclusão: Os estudos desenvolvidos identificaram a presença de alterações no alinhamento postural. As alterações foram no posicionamento da cabeça, da cervical e dos ombros entre as crianças nas fases pré-escolar e escolar, apresentando cabeça anteriorizada e ombros protusos. Também foram identificadas alterações significantes nas regiões torácica e lombar da coluna em escolares com excesso de peso corporal, evidenciando hipercifose torácica e hiperlordose lombar.

Palavras-chave: Criança. Postura. Fotogrametria. Crescimento e desenvolvimento. Obesidade pediátrica.

Keywords: Child. Posture. Photogrammetry. Growth and development. Pediatric obesity. 